\title{
EIIIA
}

Revista Eletrônica de Estudos Integrados em Discurso e Argumentação

\section{SENTIDOS DE LEGITIMAÇÃO DO ENSINO BILÍNGUE PORTUGUÊS- INGLÊS: EFEITOS DO DISCURSO INSTITUCIONAL}

\section{Laura Fortes ${ }^{\mathrm{i}}$}

Resumo: Nossa pesquisa de doutorado propôs um estudo discursivo de sentidos de bilinguismo, educação bilíngue e currículo em escolas bilíngues português-inglês. Teoricamente orientada pela análise de discurso pecheutiana, a pesquisa configurouse a partir da construção de corpora compostos de discursividades heterogêneas produzidas em torno do real da expansão dessas escolas, frequentemente justificada por uma demanda crescente pela aquisição da língua inglesa cada vez mais cedo. Apresentamos, neste artigo, um recorte de nosso corpus, a saber, o discurso institucional - constituído de dizeres que configuram o processo de construção imaginária da identidade institucional da escola - a partir de suas incidências no discurso profissional - constituído de dizeres de professores e coordenadores de escolas bilíngues português-inglês em São Paulo. Nessas condições de produção, concluímos que dois elementos constituem a base para a compreensão desse processo discursivo: 1) a representação da instituição sem falhas; 2) suas relações com discursividades da mídia e do mercado.

Palavras-chave: Ensino Bilíngue. Discurso Institucional. Mídia. Mercado.

Abstract: This paper presents a discursive analysis carried out in my doctoral research, which proposed a study of bilingualism, bilingual education and curriculum in Brazilian Portuguese-English bilingual schools. Drawing on the materialist discourse analysis framework proposed by Michel Pêcheux, it examined heterogeneous discursivities shaping the real of the fast increasing number of those schools, often justified by a growing demand for the acquisition of English at an earlier age. Research data comprised texts from four archives, two of which are approached in this paper, i.e., institutional discourse - consisting of texts that configure a process of imaginary construction of the school institutional identity - and professional discourse - consisting of interviews with teachers and coordinators of bilingual schools. Under such conditions of production, I conclude that two elements play a crucial role in developing an understanding of that discursive process: 1) the representation of a flawless institution; 2) its relations with media and market discourses.

Keywords: Bilingual Education. Institutional Discourse. Media. Market.

i Doutora em Estudos Linguísticos e Literários do Inglês pela Universidade de São Paulo (USP). Docente da Universidade Federal da Integração Latino-Americana (UNILA). E-mail: laurafortes@yahoo.com. 
EID\&A - Revista Eletrônica de Estudos Integrados em Discurso e Argumentação, Ilhéus, n. 13, jan/jun.2017.

You see this creature with her kerbstone English: the English that will keep her in the gutter to the end of her days. Well, sir, in three months I could pass that girl off as a duchess at an ambassador's garden party. I could even get her a place as lady's maid or shop assistant, which requires better English. That's the sort of thing I do for commercial millionaires. And on the profits of it I do genuine scientific work in phonetics, and a little as a poet on Miltonic lines. (SHAW, [1912] 1953, p. 228)

\section{Introdução ${ }^{1}$}

O mito de Pigmaleão, apresentado pelo poeta latino Ovídio no ano VIII d.C., conta a história desse escultor cipriota que se apaixona pela estátua que ele próprio havia esculpido². Era tão profundo seu encantamento pelo objeto criado que ele passou a viver com ela, vestindo-a, beijando-a, acariciando-a, enfim, tirando-a do lugar de simulacro à qual estava condenada pela representação escultural materializada no gelado e inerte marfim. Por meio de seu desejo, o gesto de construção do simulacro desloca-se de um artefato inanimado e ausente para uma mulher idealizada e presentificada com quem ele passa a conviver, imaginariamente, mas sem deixar, entretanto, de adornála, exaltá-la, admirá-la, venerá-la.

Em cândido marfim ele esculpira Com arte singular tão bela imagem, Que nascer não podia mais fermosa Viva mulher. Insano namorou-se Do seu mesmo trabalho, amando nele Forma admirável de gentil donzela. Tão vivo era o Retrato, que crerias Vida ter, e que passos moveria, Se o virginal rubor a não prendera; Tanta arte se ocultava na Escultura. (OVÍDIO³ apud PREDEBON, 2006, p. 521)

\footnotetext{
${ }^{1}$ A elaboração deste texto partiu de um dos capítulos apresentados em minha tese de doutorado (cf.: FORTES, 2016), desenvolvida com apoio da Fapesp (Processo n. 2012/21924-3) e da CAPES (Processo n. 3760/14-6).

${ }^{2} \mathrm{~A}$ inspiração para a referência ao mito de Pigmaleão em nosso estudo nasceu durante uma fala do Prof. Eduardo Vieira da Cunha (UFRGS) na mesa-redonda Criação e Produção no Processo Artístico coordenada pela Profa. Raquel Moreira (FURG) em 16 de outubro de 2013 no VI SEAD (Seminário de Estudos em Análise do Discurso) na Universidade Federal do Rio Grande do Sul, Porto Alegre, RS. Também participaram dessa mesa-redonda a Profa. Freda Indursky (UFRGS) e o Prof. Carlos Gerbase (PUC-RS).

3 Esta versão está apresentada na pesquisa de Predebon (2006), que se dedicou à revisão do manuscrito da tradução portuguesa das Metamorfoses de Ovídio por Francisco José Freire em 1770.
} 
EID\&A - Revista Eletrônica de Estudos Integrados em Discurso e Argumentação, Ilhéus, n. 13, jan/jun.2017.

Não foi pela mulher que Pigmaleão apaixonou-se, mas pelo seu simulacro, pela projeção de seu próprio desejo nesse jogo de ausência/presença da imagem materializada da mulher, representação tão tangível em seu imaginário.

Da mesma forma que Pigmaleão apaixonou-se por seu próprio trabalho, Henry Higgins, o professor de fonética da peça Pygmalion de George Bernard Shaw, realiza um trabalho semelhante ao de um escultor, "lapidando" a fala de Eliza Doolittle, buscando "desvencilhá-la" de seu inglês cockney e levá-la à "perfeição" do inglês dito padrão, que identificava as classes mais favorecidas.

The hardest job I ever tackled: make no mistake about that, mother. But you have no idea how frightfully interesting it is to take a human being and change her into a quite different human being by creating a new speech for her. It's filling up the deepest gulf that separates class from class and soul from soul. (SHAW, [1912] 1953, p. 271)4.

By George, Eliza, I said I'd make a woman of you; and I have. I like you like this. (SHAW, [1912] 1953, p. 305). ${ }^{5}$

Enquanto o Pigmaleão mitológico teve seu desejo realizado pelos deuses, que, comiserados, transformaram a sua estátua em mulher de carne e osso (Galatéia), o Professor Higgins viu a florista transformar-se na duquesa que ele tanto almejara. Mas ambos construíram objetos que foram fruto de sua idealização, projeção, objetos que representavam seu desejo, e que, portanto, não coincidiam com o desejo, como Shaw ([1912] 1953, p. 320) nos lembra na última frase de Pygmalion: "Galatea never does quite like Pygmalion: his relation to her is too godlike to be altogether agreeable"6.

Trazendo para o discurso o ponto fundamental de nosso argumento pela referência aos Pygmalions, poderíamos dizer que ambos os personagens constroem não apenas os seus objetos, mas uma relação imaginária com aquilo que o objeto lhes apresenta como tangível - não com a totalidade do objeto, que é impossível, uma vez que se faz presente apenas via

\footnotetext{
4 Optamos por reproduzir a tradução de Millôr Fernandes (SHAW, [1912] 2011, p. 96): "É a tarefa mais difícil que eu já me propus; não brinque com isso a senhora, minha mãe. É claro que é diabolicamente fascinante pegar um ser humano e transformá-lo em outro dando-lhe uma aparelhagem vocabular totalmente nova. Tenho a sensação de que estou enchendo o fosso que separa classe de classe e alma de alma".

5 "Diabos me carreguem, Eliza, eu disse que ia fazer de você uma mulher - e fiz! É assim que eu gosto de você". (SHAW, [1912] 2011, p. 153).

6 "Galatea não gosta muito de Pigmaleão; a relação dele com ela é demasiado divina pra ser agradável”. (SHAW, [1912] 2011, p. 172).
} 
EID\&A - Revista Eletrônica de Estudos Integrados em Discurso e Argumentação, Ilhéus, n. 13, jan/jun.2017.

representação7. Diríamos que a vida dos simulacros criados por Pigmaleão e Higgins constitui uma ilusão à qual eles se identificam para fazer sentido, o que implica necessariamente uma interpelação - trabalho da ideologia, pois, como nos ensina Althusser (2007 [1969], p. 85): "a ideologia representa a relação imaginária dos indivíduos com suas condições reais de existência", ou seja, a ideologia é concebida como "ilusão/alusão" (ALTHUSSER 2007 [1969], p. 86). Assim, é a representação dessa relação imaginária que produz o sujeito, i.e., a evidência de sua unidade imaginária, ao mesmo tempo em que produz a evidência da transparência do sentido no processo que Pêcheux (1988a [1975]) denominou "interpelação-identificação". Nesse momento de sua reflexão teórica, Pêcheux faz referência explícita à concepção psicanalítica de sujeito trazida por Lacan, buscando aproximá-la da teorização althusseriana de ideologia. Nessa aproximação teórica, Pêcheux propõe que, pelo trabalho do inconsciente, o sujeito esquece ${ }^{8}$ esse exterior que 0 determina, esquecimento que significa "o acobertamento da causa do sujeito no próprio interior de seu efeito" (PÊCHEUX 1988a [1975], p. 183, nota 32), sendo esta a condição de seu assujeitamento ideológico e de sua identificação às determinações do interdiscurso. Assim, como nos lembra Pêcheux em seu "início de uma retificação" ao final de Semântica e discurso, tal determinação não é plena e o assujeitamento ideológico não se realiza sem a possibilidade de falhas, pois há, também, o trabalho do "inconsciente, isto é, a causa que determina o sujeito exatamente onde o efeito de interpelação o captura" (PÊCHEUX [1978] 1988b, p. 300), produzindo, imaginariamente, a sua unidade e a univocidade do sentido.

A relação dos Pygmalions com seus respectivos simulacros, com o que iniciamos este texto, é, portanto, imaginária, pois somente a partir da representação dessa relação que os sujeitos podem ser constituídos. Nessa relação imaginária, a coincidência entre o desejo e o objeto torna-se possível, produz sentidos para o sujeito por meio de sua identificação com sua própria projeção - efeito de "realidade", de "literalidade", em que o sujeito é capturado no processo de interpelação. É no imaginário que a causa e o efeito

\footnotetext{
7 Lembramos que nossa referência aqui é meramente ilustrativa e não desenvolve suficientemente o tema da representação, tão magistralmente abordado por Michel Foucault em obras como As palavras e as coisas (FOUCAULT, [1966] 1999) e Isto não é um cachimbo (FOUCAULT, [1973] 1988).

8 Não é deliberadamente que o sujeito esquece, mas sim pelo trabalho do inconsciente. Nas palavras de Lacan ([1971] 2009, p. 42), “[o] inconsciente não quer dizer nada, se não quiser dizer que, diga eu o que disser e onde quer que me posicione, mesmo que me posicione bem, eu não sei o que digo; e nenhum dos discursos, tais como os defini no ano passado, dá esperança, permite a alguém pretender, até esperar, de algum modo, saber o que diz".
} 
EID\&A - Revista Eletrônica de Estudos Integrados em Discurso e Argumentação, Ilhéus, n. 13, jan/jun.2017.

do sujeito se realizam: causa e efeito de sua própria existência, que lhe é apresentada como transparente e originada em seu interior. As falhas desse processo de interpelação-identificação não são percebidas/assimiladas pelos sujeitos, mas são apresentadas ao leitor nas constantes incertezas do jogo presença/ausência produzido pelas imagens - construídas imaginariamente de seus objetos de adoração.

A alusão aos Pygmalions na designação de uma das categorias de análise de nosso corpus de pesquisa busca uma articulação entre a reflexão teórica que acabamos de apresentar e a análise das incidências do discurso institucional sobre o discurso profissional9. Nesse processo, priorizou-se a dimensão das representações imaginárias - que, como veremos, estão construídas em torno de sentidos de legitimação de um "ideal": práticas de ensino "ideais", alunos "ideais", sentidos construídos pela exterioridade do interdiscurso e que retornam ao discurso do sujeito como se fossem "seu" discurso pelo processo de interpelação-identificação. Assim como a estátua talhada pelo Pigmaleão ovidiano e a lady gerada pelo Pygmalion moderno corporificado em Higgins, as representações imaginárias das instituições escolares bilíngues constituem espaços de "perfeição" com os quais os sujeitos constroem relações que configuram suas identidades e que os afetam na (im)possibilidade de alcançar seu desejo de completude, de plenitude.

Assim, neste texto, nossa leitura do arquivo do discurso profissional focaliza seu atravessamento pelo discurso institucional em dois movimentos de interpretação: 1) como um processo discursivo especialmente marcado pela representação da instituição escolar bilíngue como uma instituição sem falhas; 2) como um processo discursivo fortemente sustentado por discursividades da mídia e do mercado.

\section{Venerando a criação: efeitos de legitimação de uma instituição sem falhas}

Efeitos de sentido de legitimação perpassam as discursividades sobre o ensino bilíngue português-inglês em diversos campos, especialmente em textualidades da mídia, da academia e da divulgação institucional (FORTES, 2016). Tal efeito de legitimação parece afetar dizeres que constituem o discurso profissional, no qual o "eu" que emerge na materialidade linguística

\footnotetext{
9 Em nosso contexto de pesquisa (FORTES, 2016), o arquivo que denominamos "discurso profissional" foi composto por entrevistas semiestruturadas realizadas com professores e coordenadores atuando em três escolas bilíngues português-inglês na cidade de São Paulo.
} 
EID\&A - Revista Eletrônica de Estudos Integrados em Discurso e Argumentação, Ilhéus, n. 13, jan/jun.2017.

configura-se a partir de fortes marcas de um lugar institucional incidindo sobre o dizer do sujeito.

Para analisar esse processo discursivo, será importante que tenhamos em mente a reivindicação de Fuchs e Pêcheux ([1975] 1997, p. 171) por "uma teoria não-subjetiva da constituição do sujeito em sua situação concreta de enunciador". Isso significa considerar o sujeito como efeito e não como fonte de sentido, uma vez que

[...] está limitado em seu dizer pelo não dito e pelo não dizível de sua inserção na sociedade humana em geral e nessa formação social em particular. [...] ele não fala, mas "é falado" pelo lugar de sujeito ideológico que veio a ocupar. E, no entanto, numa perspectiva behaviorista ou fisiológica, fala. Mas fala considerando-se autor de seu discurso, desde uma posição imaginária. (BRAUNSTEIN, 2008 [1980], p.76, tradução nossa ${ }^{10}$ )

Tal posição imaginária a partir da qual o sujeito enuncia produz a ilusão de que é origem de seu dizer e a ilusão de que é uno, centrado, expressandose por uma "protonoção de 'eu"' (SAAL; BRAUNSTEIN, 2008 [1980], p.110, tradução nossa"1), que constitui a representação de uma unidade imaginária, efeito do trabalho da interpelação ideológica: "os indivíduos são sempre/já sujeitos" (ALTHUSSER, 2007 [1969], p. 98, grifos do autor).

Tal representação de "individualidade" constitui-se, assim, pelo processo de interpelação ideológica, que produz a ilusão da unidade do "eu", apagando sua exterioridade histórica. Mas, como nos ensina Pêcheux, o efeito-sujeito não se produz apenas pela interpelação ideológica, mas também pelo processo de identificação imaginária.

Uma última precisão a propósito do termo identificação: o fato de que a evidência do sentido (a produção do sentido no non-sens) seja estritamente contemporânea à interpelação do indivíduo em sujeito de seu discurso se exprime, como dissemos, por sua identificação com a formação discursiva que o domina, onde ele se encontra "encravado" na condição de sujeito - e esse "encravamento" se desloca juntamente com a própria dominância no decorrer da "formação" do sujeito. Trata-se, pois de uma identificação imaginária que diz respeito à "gênese do ego", ao ajustamento sempre inacabado do sujeito consigo mesmo [...], à sua identificação com os traços do objeto na representação que o sujeito "possui" desse objeto... (PÊCHEUX, 1988a [1975], p. 265).

\footnotetext{
${ }^{10}$ Texto original: "[...] está limitado en su decir por lo no dicho y por lo no decible de su inserción en la sociedad humana en general y en esa formación social en particular. [...] él no habla sino que 'es hablado' por el lugar de sujeto ideológico que ha venido a ocupar. Y, sin embargo, desde una perspectiva conductista y fisiológica, habla. Pero habla considerándose autor de su discurso, desde una posición imaginaria". (BRAUNSTEIN, 2008 [1980], p.76).

"Texto original: “protonoción de 'yo"” (SAAL; BRAUNSTEIN, 2008 [1980], p. 110).
} 
EID\&A - Revista Eletrônica de Estudos Integrados em Discurso e Argumentação, Ilhéus, n. 13, jan/jun.2017.

A evidência do sujeito como um "eu" uno e centrado produz-se ao mesmo tempo em que ele é capturado pela evidência de sentido transparente e unívoco ao identificar-se com certa formação discursiva - exterioridade necessariamente "esquecida" pelo sujeito. Esse processo de identificação imaginária se dá pela dupla interpelação do sujeito pela ideologia e pelo inconsciente, pois "[o] sujeito é sempre, e ao mesmo tempo, sujeito da ideologia e sujeito do desejo inconsciente e isso tem a ver com o fato de nossos corpos serem atravessados pela linguagem antes de qualquer cogitação" (HENRY [1977] 1992, p. 188-9).

A partir do recorte do arquivo do discurso profissional constituído para esta análise, foi possível identificar um efeito de legitimação da escola bilíngue português-inglês sendo produzido pelos dizeres de sujeitos-professores e de sujeitos-coordenadores. Nesse discurso, o "eu" que emerge na materialidade linguística configura-se a partir de fortes marcas de um lugar institucional incidindo sobre o dizer do sujeito.

Na sequência discursiva 1 a seguir ${ }^{12}$, temos a interpelação-identificação do sujeito com a representação de sua individualidade enquanto enunciador por meio da materialidade linguística dos indicadores de $1^{\text {a }}$ pessoa "eu" e "a gente", como destacamos:

1_SC_2_A: [...] eu me sinto muito responsável... por esse carimbo de bilíngue né? eu tenho que/ eu tenho que... entregar esse serviço bem feito... então eu me sinto muito responsável e/ eu estou sempre buscando essa/ essa qualidade esse controle dessa qualidade porque eu sei que eu não posso chamar de bilíngue e não estar né? dando esse serviço que a gente está vendendo aqui né?

Entretanto, o deslizamento da referência do "eu" para "a gente" constitui um equívoco que deixa escapar a não coincidência do dizer com o sujeito da enunciação ("eu"), que permanece identificado com a sua representação de individualidade, um efeito para o sujeito. Esse equívoco funciona pela inconsistência da referência e deixa entrever o lugar de constituição desses sentidos de ensino vinculados a um "serviço" - lugar que não se fixa no sujeito singular ("eu"), mas desliza para um lugar institucional de produção de sentidos materializado num movimento de pluralização desse

\footnotetext{
12 A fim de manter a identidade dos participantes em sigilo, todos os nomes próprios foram trocados e as escolas foram designadas Escola A, Escola B e Escola C, de acordo com a ordem em que foram realizadas as entrevistas. Os seguintes códigos de referência foram usados para os sujeitos: P - pesquisadora; SP - sujeito-professor; SC - sujeito-coordenador; 1, 2 - atuação de acordo com o nível de ensino: 1 para Anos Iniciais do Ensino Fundamental (EB I) e 2 para Anos Finais do Ensino Fundamental (EB II). A, B, C - unidade escolar.
} 
EID\&A - Revista Eletrônica de Estudos Integrados em Discurso e Argumentação, Ilhéus, n. 13, jan/jun.2017.

sujeito no sintagma "a gente". As marcas de um "enunciador-individual" que se confundem com um lugar de enunciação institucional aparecem numa materialidade similar nas seguintes sequências discursivas:

2_SP_2_B: [...] aqui para mim o programa é/ é excelente

3_SP_2_B: [...] acho que ESTOU satisfeita em estar em um programa bilíngue porque eu acho que ele realmente funciona

4_SC_2_C: [...] eu ainda acredito que a educação bilíngue na Escola $C$ é uma educação bilíngue que tem um foco que me agrada bastante e que eu acredito muito e que eu compro muito

5_SC_2_C: [...] eu gosto muito de trabalhar aqui... eu acredito MUITO no que a gente FAZ... e a gente:::: é assim eu acho que... a BASE do trabalho da Escola C e eu sei que seu/ o seu foco É no bilinguismo... mas eu acho que para além do bilinguismo é como se constitui essa educação bilíngue... [...] a gente VIVE uma educação bilíngue... que eu nã:::::::/ até hoje eu não vi em lugar nenhum... tudo bem... a gente acredita que é uma BOA educação bilíngue não teria uma melhor do que as outras... mas a gente acredita no que a gente faz

6_SC_2_C: [...] tem MUITO pesquisador... trabalhando aqui... exatamente pra gente BUSCAR uma EXCELÊNCIA e uma retidão... nesse sonho da Maria que é a dona da escola... né? então assim ela nos CONVOCA a contribuir com esse sonho... com a realização desse sonho...

7_SC_2_C: [...] a escola é planejada dessa forma ela é SONHADA dessa forma então a escola É... um espaço um contexto... BILÍNGUE dentro de uma São Paulo... que não é tão bilíngue assim... né?... dentro de um país Brasil que não é nada bilíngue... então a gente realmente tem o nosso jardim secreto... Escola C... ((rindo)) que:: eh::: nos possibilita dentro dos nossos muros PROPORCIONAR esta/ este contexto

Embora as marcas linguísticas indiquem a $1^{\mathrm{a}}$ pessoa como "enunciadorindividual", tal individualidade constitui apenas um efeito, como temos tentado demonstrar. As posições discursivas "professor" e "coordenador" aparecem recobertas pelo lugar de dizer do enunciador-individual "eu”, que, por sua vez, encontra-se atravessado pelo discurso institucional, identificado tanto pelas marcas linguísticas de exaltação da instituição, nas sequências 1 a 7, como pelo deslizamento do indicador de $1^{\text {a }}$ pessoa do singular ("eu”) para o indicador de $1^{\text {a }}$ pessoa do plural ("a gente"), nas sequências 1 e 5 .

Nesse processo discursivo, o sujeito encontra-se interpelado-identificado com uma representação imaginária da instituição como um lugar "sem falhas", materializada nos sintagmas/significantes "serviço bem feito", "controle dessa qualidade” (sequência 1), “o programa é excelente” (sequência 2), "ele 
EID\&A - Revista Eletrônica de Estudos Integrados em Discurso e Argumentação, Ilhéus, n. 13, jan/jun.2017.

[programa bilíngue] realmente funciona" (sequência 3), "educação bilíngue que tem um foco que me agrada bastante e que eu acredito muito e que eu compro muito" (sequência 4), "eu gosto muito de trabalhar aqui", "eu acredito muito no que a gente faz", "a gente vive uma educação bilíngue que [...] até hoje eu não vi em lugar nenhum", "a gente acredita que é uma boa educação bilíngue", "a gente acredita no que a gente faz" (sequência 5), "exatamente pra gente buscar uma excelência e uma retidão" (sequência 6), "a gente realmente tem o nosso jardim secreto... Escola C [...] que nos possibilita dentro dos nossos muros proporcionar [...] este contexto" (sequência 7). Especialmente na sequência 7, as metáforas do "jardim secreto" e do "sonho" são evocadas, mostrando um sujeito identificado com marcas de um dizer institucional que se produz na possibilidade de alcançar algo excepcional, utópico - a estátua de Pigmalião, a Eliza do professor Higgins... o "impossível” tornado "possível” na e por meio da instituição, que se constrói num lugar de realizações que não podem ser alcançáveis fora dela.

\section{Relações entre o discurso institucional e as discursividades da mídia e do mercado}

Em nossa pesquisa de doutorado (FORTES, 2016), concluímos que uma das discursividades mais proeminentes sobre as escolas bilíngues portuguêsinglês aparece nas textualidades colocadas em circulação pela mídia jornalística, que, desde a década de 2000, vem dando destaque ao aumento do número desses estabelecimentos de ensino no "mercado", enfatizando as "vantagens" da educação bilíngue. O discurso da mídia parecia instaurar, assim, um dos espaços do "dizível" (ORLANDI, [1990] 2008; [1992] 2002a) sobre a educação bilíngue no Brasil, dando-lhe visibilidade a partir de determinados sentidos. Na matéria Cresce procura por escolas bilíngues no país (AGÊNCIA ESTADO, 2010), por exemplo, o "fenômeno" educacional do "bilinguismo" aparece assim enunciado:

O número de escolas bilíngues no Brasil saltou de 145 em 2007 para 180 em 2009, registrando um aumento de $24 \%$ no período. Neste ano, outros sete colégios estão abrindo as portas só em São Paulo. O surgimento de novas instituições revela um nicho educacional disputado, que se tornou sonho de consumo de famílias de classe média e alta. (AGÊNCIA ESTADO, 2010).

A intensificação da circulação de informações sobre as escolas bilíngues na mídia constitui um movimento de regulação de sentidos não apenas sobre 
EID\&A - Revista Eletrônica de Estudos Integrados em Discurso e Argumentação, Ilhéus, n. 13, jan/jun.2017.

essa modalidade de ensino, mas também sobre as línguas em questão - o português e o inglês, no caso - e sobre os processos de aquisição de línguas evocados pelo significante "bilinguismo". Assim, certos sentidos (e não outros) são colocados em circulação pela mídia: sentidos de exaltação de uma "vantagem bilíngue", que produzem uma representação do bilinguismo e da educação bilíngue como saberes legitimados sobre (a relação entre o sujeito e) a língua, com marcas de discursividades do mercado ("nicho educacional disputado", "sonho de consumo"). As manchetes a seguir ilustram a circulação de sentidos dessa "vantagem bilíngue":

Aprendizado precoce: Quanto mais cedo, mais fácil - Folha de São Paulo $(26 / 08 / 2003)^{13}$

Por um cérebro bilíngue - Revista Educação (14/07/2011)14

Fluência em um segundo idioma e acesso ao estudo no exterior atraem brasileiros para escolas bilíngues - O Globo (24/01/2008) ${ }^{15}$

Bebês têm aula de inglês antes mesmo de falar - Folha de São Paulo (12/06/2011) ${ }^{16}$

Crianças bilíngues têm mais facilidade na alfabetização - O Estado de São Paulo $(09 / 02 / 2012)^{17}$

Falar duas línguas desde cedo é positivo - O Estado de São Paulo (23/09/2013) ${ }^{18}$

Em um estudo discursivo sobre o ensino de inglês para crianças no Brasil, Garcia (2011) identificou o enunciado "quanto mais cedo, melhor" como predominante na produção de sentidos sobre o ensino da língua inglesa nesse contexto educacional. Tal enunciado perpassa esses dizeres, construindo a necessidade da aprendizagem precoce de inglês. Desse modo, nas textualidades da mídia, a escola bilíngue português-inglês é predominantemente significada como um lugar em que a demanda por esse tipo de aprendizagem seria contemplada plenamente, retroalimentando os sentidos da "vantagem bilíngue", principalmente a partir da comparação com a modalidade de ensino de inglês em escolas regulares não-bilíngues.

\footnotetext{
${ }^{13}$ Cf. referência completa em Almeida (2003).

${ }^{14}$ Cf. referência completa em Corrêa (2011).

${ }^{15}$ Cf. referência completa em Matuck (2010).

${ }^{16}$ Cf. referência completa em Gois e Rewald (2011).

${ }^{17}$ Cf. referência completa em Milena (2012).

${ }^{18}$ Cf. referência completa em Mattos (2013).
} 
EID\&A - Revista Eletrônica de Estudos Integrados em Discurso e Argumentação, Ilhéus, n. 13, jan/jun.2017.

Desse modo, no funcionamento do discurso da mídia sobre a educação bilíngue português-inglês, a instituição que oferece tal modalidade de ensino é significada como um lugar de "perfeição" a ser desejado (e consumido) por toda a sociedade (FORTES, 2016). Segundo Payer (2005), a mídia pode ser compreendida como o texto fundamental do mercado, o novo grande Sujeito da sociedade contemporânea, cujo "enunciado todo-poderoso [...], que funciona como lugar máximo de interpelação, pode ser resumido em uma palavra: 'sucesso'" (PAYER, 2005, p. 18, grifos da autora). As sequências discursivas que trouxemos para análise mostram como os sujeitos são interpelados-identificados por esse enunciado ao (se) significarem em relação à educação bilíngue, evocando frequentemente um lugar de legitimação da instituição na qual estão inseridos.

Em alguns momentos, foi possível identificar que o movimento de sentidos em torno desse lugar de legitimação ancora-se no modo de interpelação ideológica do mercado, numa racionalidade da educação como mercadoria e, portanto, passível de ser mensurada quanto a sua "qualidade" e "eficácia". Um dos espaços do dizível sobre a educação bilíngue portuguêsinglês encontra-se, assim, marcado por discursividades do mercado que colocam em circulação o significante "bilíngue" para funcionar metonimicamente como uma marca de legitimação do ensino, um lugar, portanto, desejado por muitas instituições escolares do setor privado. Assim, o efeito de legitimação das escolas bilíngues aparece relacionado à historicidade em funcionamento no processo metonímico de produção de sentidos sobre essas instituições. Retomemos a formulação 1, que analisamos na seção anterior e que ilustra como o sujeito (se) significa pela interpelaçãoidentificação provocada pelo significante "bilíngue" num recorte do real marcado pela interseção com discursividades de mercado.

1_SC_2_A: [...] eu me sinto muito responsável... por esse carimbo de bilíngue né? eu tenho que/ eu tenho que... entregar esse serviço bem feito... então eu me sinto muito responsável e/ eu to sempre buscando essa/ essa qualidade esse controle dessa qualidade porque eu sei que eu não posso chamar de bilíngue e não estar né? dando esse serviço que a gente está vendendo aqui né?

A materialidade linguística que constitui o fio discursivo produz certos efeitos de sentido sobre a instituição escolar que a vinculam a um negócio cujo serviço oferecido/vendido é a modalidade de educação bilíngue. $O$ sujeito encontra-se capturado pelo efeito de evidência dessa representação - pelo 
EID\&A - Revista Eletrônica de Estudos Integrados em Discurso e Argumentação, Ilhéus, n. 13, jan/jun.2017.

trabalho da ideologia -, assumindo a "responsabilidade" pela entrega do "serviço bem feito", pelo "controle de qualidade", pelo "serviço vendido".

Ao analisar o espaço geográfico em sua relação com processos de urbanização, Milton Santos (2005 [1996]) destaca a ampliação/renovação do setor terciário diante das condições da "economia internacional mundializada" (SANTOS, 2005 [1996], p. 79) e lista uma série de atividades primordiais para o seu funcionamento (marketing, engenharia, gerenciamento, etc.), apontando a expansão do setor e das necessidades criadas por ele.

A ampliação qualitativa e quantitativa das necessidades ligadas à existência individual e das famílias junto ao fato de que o próprio sistema econômico dispõe dos meios de criar e impor novas necessidades como se elas fossem naturais são, paralelamente, criadores de novas atividades que se enquadram também dentro do terciário (saúde, religião, diversões, turismo e tantas outras). Onde incluir a atividade educacional? (SANTOS, 2005 [1996], p. 80, grifos nossos).

O geógrafo brasileiro analisa a expansão do setor terciário na forma de novas atividades cujas necessidades são impostas pela globalização (ou "economia internacional mundializada", nas palavras de Milton Santos). Ora, se como o próprio autor afirma, tais necessidades são impostas "como se elas fossem naturais", a operação de "imposição" não pode ser considerada senão pela via da ideologia em sua relação intrínseca com o campo do imaginário - pois, como já explicamos com Althusser (2007 [1969], p. 85), "a ideologia representa a relação imaginária dos indivíduos com suas condições reais de existência”. Nessa perspectiva, as atividades do setor terciário constituem as condições reais de existência dos indivíduos, mas somente se tornam necessárias a eles pela interpelação ideológica que produz a ilusão dessa necessidade.

E Santos (2005 [1996], p. 80) nos deixa a pergunta instigante sobre o lugar da atividade educacional nessa reorganização do setor terciário: "Onde incluir a atividade educacional?" - pergunta que pode ser respondida a partir de uma leitura discursiva da formulação que estamos analisando. Tal formulação se torna possível - "a condição do legível em relação ao próprio legível", nos termos de Pêcheux (1999 [1983], p. 52) - a partir do momento em que consideramos a exterioridade histórico-econômico-social tão bem teorizada pelo geógrafo brasileiro ao tratar dos processos de globalização e de urbanização no Brasil e no mundo. Assim, é "evidente" e "natural" que o sujeito enuncie que se sinta "responsável pelo carimbo de bilíngue" - como se 
EID\&A - Revista Eletrônica de Estudos Integrados em Discurso e Argumentação, Ilhéus, n. 13, jan/jun.2017.

fosse um selo de garantia, da mesma forma que a $\mathrm{OEBi}^{19}$ se coloca como uma organização que legitima o trabalho das instituições escolares bilíngues. Do mesmo modo, é possível enunciar que é preciso "entregar esse serviço bem feito", quando o "serviço" enquadra-se ao que Milton Santos colocou em sua pergunta como "atividade educacional". E, enfim, falar em "qualidade" e "controle de qualidade" figura no eixo paradigmático de possibilidades de dizer sobre a educação e, mais especificamente, sobre a educação bilíngue.

\section{Considerações finais}

Nossa leitura centralizou as discussões em torno do discurso institucional como um lugar de produção de um imaginário sobre a escola bilíngue cuja base significante predominante está na legitimação pela veneração de sua imagem. Daí a alusão ao personagem Pygmalion - tanto o de Ovídio, que admirava incessantemente a estátua esculpida por suas próprias mãos, quanto o de Shaw, que, encarnado na figura do professor Higgins, se gabava de ter transformado Eliza Doolittle em uma lady. Porque acreditaram demasiadamente em suas criações, os Pygmalions se viam atraídos cegamente por seus ideais de perfeição, que se tornaram parte de sua própria identidade. Similarmente, as representações imaginárias das instituições escolares bilíngues constituem o que formulamos como a construção discursiva da legitimação espaços de "perfeição" pelos quais os sujeitos são interpelados-identificados, afetando a configuração de suas subjetividades na (im)possibilidade de alcançar seu desejo de completude, de plenitude.

A análise discursiva permitiu, num segundo movimento de interpretação, delinear a representação da instituição escolar bilíngue como uma instituição sem falhas, funcionando a partir de sua sustentação em discursividades do mercado e da mídia, num processo de seleção, organização e circulação de sentidos que denominamos uma metonímia de celebração da vantagem bilíngue (FORTES, 2016). Os efeitos de sentido filiados a essas discursividades foram compreendidos a partir do processo histórico-econômico da inserção do campo da educação no setor terciário nas condições impostas pela "economia internacional mundializada" (SANTOS, 2005 [1996], p. 79) do neoliberalismo. Essa inserção criou novas possibilidades de dizer sobre a educação, fazendo irromper

19 OEBi (Organização das Escolas Bilíngues do Estado de São Paulo), uma organização privada fundada em 2000 e cujo foco é oferecer suporte didático-pedagógico às escolas bilíngues que se associem à instituição. 
EID\&A - Revista Eletrônica de Estudos Integrados em Discurso e Argumentação, Ilhéus, n. 13, jan/jun.2017.

significantes outrora restritos ao campo da economia/mercado, tais como "serviço" e "(controle de) qualidade", por exemplo, que passaram a fazer parte de um repertório de marcas linguísticas de exaltação/glorificação da instituição, produzindo representações da escola bilíngue como um "lugar sem falhas".

As breves considerações tecidas neste texto permitem-nos formular, finalmente, que o efeito de legitimação da instituição bilíngue funciona como um simulacro que vem ocupar o lugar de uma falta - uma falta que formulamos como uma ausência de determinações regulamentadoras acerca do funcionamento de escolas bilíngues português-inglês (FORTES, 2016). Tal ausência, especialmente circunscrita em torno de uma regulamentação curricular, foi apontada em algumas pesquisas (cf.: CORREDATO, 2010; FÁVARO, 2009; GARCIA, 2011; GIMENEZ, 2010, 2013; MOURA, 2009, 2010)20 , que mostram uma preocupação com a falta de produção de espaços de regulação específica - lacuna que pode impactar o trabalho do professor em diversas dimensões e também produzir seus efeitos na educação da sociedade brasileira em geral, uma vez que a falta de regulamentação acaba ampliando as possibilidades de oferta dessa modalidade de ensino pela iniciativa privada. Como consequência, tais modalidades de ensino transformam-se em novos "nichos de mercado" (GIMENEZ, 2010, p. 14), que são colocados em intensa circulação pelo discurso midiático, dando visibilidade e legitimação a representações de língua como "produto" e de ensino como "serviço", tal como analisamos neste artigo.

\section{Fontes}

AGÊNCIA ESTADO. Cresce procura por escolas bilíngues no País. O Estado de São Paulo. 22/01/2010. Disponível em: <http://www.estadao.com.br/noticias/geral,cresceprocura-por-escolas-bilingues-no-pais,499839,o.htm>. Acesso em 22 abr. 2011.

ALMEIDA, Alexandra Ozorio de. Aprendizado precoce: quanto mais cedo, mais fácil. In: Folha de São Paulo. 26/08/2003. Disponível em: <http://www1.folha.uol.com.br/folha/sinapse/ult1063u538.shtml>. Acesso em: 24 jul. 2012.

CORRÊA, M. C. Por um cérebro bilíngue. In: Revista Educação. 10/09/2011. Disponível em: <http://revistaeducacao.uol.com.br/formacao-docente/111/artigo233962-1.asp>. Acesso em: 24 jul. 2012.

${ }^{20}$ Essas pesquisas, filiadas ao campo de estudos da LA, constituem gestos de interpretação daquilo que delineamos como espaços do silêncio do discurso político-educacional (FORTES, 2016). 
EID\&A - Revista Eletrônica de Estudos Integrados em Discurso e Argumentação, Ilhéus, n. 13, jan/jun.2017.

GOIS, Antônio; REWALD, Fabiana. Bebês têm aula de inglês antes mesmo de falar. Folha de São Paulo. 12/06/2011. Disponível em: <http://www1.folha.uol.com.br/fsp/cotidian/ff1206201101.htm>. Acesso em 21 set. 2011.

MATTOS, Thiago. Falar duas línguas desde cedo é positivo. 16/09/2013. Estadão.com.br (Grupo Estado). Disponível em: $<$ http://educacao.estadao.com.br/noticias/geral,falar-duas-linguas-desde-cedo-epositivo,1075473>. Acesso em: 23 set. 2013.

MATUCK, Fadua. Fluência em um segundo idioma e acesso ao estudo no exterior atraem brasileiros para escolas bilíngues. O Globo. 24/01/2008. Disponível em: <http://oglobo.globo.com/sociedade/educacao/fluencia-em-um-segundo-idiomaacesso-ao-estudo-no-exterior-atraem-brasileiros-para-escolas-3851026>. Acesso em: 13 dez. 2010.

MILENA, A. Crianças bilíngues têm mais facilidade na alfabetização, diz estudo. Estadão.com.br (Grupo Estado). 09/02/2012. Disponível em: <http://saude.estadao.com.br/noticias/geral,criancas-bilingues-tem-mais-facilidadena-alfabetizacao-diz-estudo,833460>. Acesso em 19 fev. 2012.

SHAW, George Bernard. Pygmalion. In: SHAW, G. B. Four plays by George Bernard Shaw: Candida, Cesar and Cleopatra, Pygmalion, Heartbreak House. Introduction by Louis Kronenberger. New York: The Modern Library, 1953 [1912].

SHAW, George Bernard. Pigmaleão. Trad. Millôr Fernandes. Porto Alegre: L\&PM, 2011 [1912].

\section{Referências}

ALTHUSSER, Louis. Aparelhos ideológicos de Estado: nota sobre os aparelhos ideológicos de Estado. Trad. Walter José Evangelista e Maria Laura Viveiros de Castro. 10.ed. Rio de Janeiro: Graal, 2007 [1969].

FORTES, Laura. Entre o silêncio e o dizível: um estudo discursivo de sentidos de bilinguismo, educação bilíngue e currículo em escolas bilíngues português-inglês. 444 f. Tese (Doutorado). Faculdade de Filosofia, Letras e Ciências Humanas, Universidade de São Paulo, São Paulo, 2016.

BRAUNSTEIN, Néstor. Sujeto de la conciencia, sujeto del discurso, sujeto. In:

Psiquiatría, teoría del sujeto, psicoanálisis (hacia Lacan). Cd. de México: Siglo veintiuno Ed., 2008 [1980]. p. 69-79.

CORREDATO, Vanessa. D. O Ensino Bilíngue em São Paulo: práticas de imersão em um contexto monolíngue. Monografia (Especialização). Anhanguera Educacional, 2010. 
EID\&A - Revista Eletrônica de Estudos Integrados em Discurso e Argumentação, Ilhéus, n. 13, jan/jun.2017.

FÁVARO, Fernanda Meireles. A educação infantil bilíngue (português/inglês) na cidade de São Paulo e a formação dos profissionais da área: um estudo de caso. Dissertação (Mestrado), Pontifícia Universidade Católica de São Paulo, São Paulo, 2009.

FOUCAULT, Michel. As palavras e as coisas: uma arqueologia das ciências humanas. Trad. Salma Tannus Muchail. 8. ed. São Paulo: Martins Fontes, 1999 [1966].

FOUCAULT, Michel. Isto não é um cachimbo. Trad. Jorge Coli. Rio de Janeiro: Paz e Terra, 1998 [1973].

FUCHS, Catherine; PÊCHEUX, Michel. A propósito da Análise Automática do Discurso: Atualização e Perspectivas. Trad. Péricles Cunha. In: GADET, Françoise; HAK, Tony. (Org..) Por uma Análise Automática do Discurso: uma Introdução à obra de Michel Pêcheux. Tradutores: Bethania S. Mariani... [et al.]. 3.ed. Campinas: Editora da UNICAMP, 1997 [1975].

GARCIA, Bianca. Quanto mais cedo melhor (?): uma análise discursiva do ensino de inglês para crianças. 216 p. Dissertação (Mestrado), Faculdade de Filosofia, Letras e Ciências Humanas da Universidade de São Paulo, 2011.

GIMENEZ, Telma. Apresentação. In: ROCHA, Claudia Hilsdorf, TONELLI, Juliana Reichert Assunção; SILVA, Kleber Aparecido da (Org.). Língua estrangeira para crianças: ensino-aprendizagem e formação docente. Campinas, Pontes, 2010, p. 13-25.

GIMENEZ, Telma. A ausência de políticas para o ensino da língua inglesa nos anos iniciais de escolarização no Brasil. In: NICOLAIDES, Christiane; SILVA, Kleber Aparecido da; TíLIO, Rogério; ROCHA, Claudia Hilsdorf (Org.). Política e Políticas Linguísticas. Campinas: Pontes Editores, 2013. p. 199-218.

HENRY, Paul. A ferramenta imperfeita: Língua, sujeito e discurso. Trad. Maria Fausta P. de Castro. Campinas: Editora da Unicamp, 1992.

LACAN, Jacques. Seminário, livro 18: de um discurso que não fosse semblante Texto estabelecido por Jacques-Alain Miller; tradução Vera Ribeiro; versão final Nora Pessoa Gonçalves; preparação de texto André Telles. Rio de Janeiro: Jorge Zahar Ed., 2009 [1971].

MOURA, Selma de Assis. Com quantas línguas se faz um país? Concepções e práticas de ensino em uma sala de aula na educação bilíngue. Dissertação (Mestrado), Faculdade de Educação da Universidade de São Paulo, São Paulo, 2009.

MOURA, Selma de Assis. Educação bilíngue e currículo: de uma coleção de conteúdos a uma integração de conhecimentos. In: ROCHA, Claudia Hilsdorf, TONELLI, Juliana Reichert Assunção; SILVA, Kleber Aparecido da (Org.). Língua estrangeira para crianças: ensino-aprendizagem e formação docente. Campinas: Pontes, 2010. p. 269-295.

ORLANDI, Eni Puccinelli. As formas do silêncio: no movimento dos sentidos. 5.ed. Campinas. Editora da Unicamp, 2002a [1992]. 
EID\&A - Revista Eletrônica de Estudos Integrados em Discurso e Argumentação, Ilhéus, n. 13, jan/jun.2017.

ORLANDI, Eni Puccinelli. Silêncio e sentido. In: ORLANDI, Eni Puccinelli. Terra à vista: discurso do confronto: velho e novo mundo. 2.ed. Campinas: Editora da Unicamp, 2008 [1990]. p. 57-61.

PAYER, Maria Onice. Linguagem e sociedade contemporânea: sujeito, mídia, mercado. Revista Rua, Núcleo de Desenvolvimento da Criatividade da Unicamp, n. 11, mar. 2005. p. 9-25.

PÊCHEUX, Michel. Semântica e discurso: uma crítica à afirmação do óbvio. Trad. Eni Pulcinelli Orlandi, Lourenço Chacon Jurado Filho, Manoel Luiz Gonçalves Corrêa, Silvana Mabel Serrani. Campinas: Editora da UNICAMP, 1988a [1975].

PÊCHEUX, Michel. Só há causa daquilo que falha ou o inverno político francês: início de uma retificação. In: PÊCHEUX, Michel. Semântica e discurso: uma crítica à afirmação do óbvio. Trad. Eni Pulcinelli Orlandi, Lourenço Chacon Jurado Filho, Manoel Luiz Gonçalves Corrêa, Silvana Mabel Serrani. Campinas: Editora da UNICAMP, 1988b [1978]. p. 293-307.

PÊCHEUX, Michel. Papel da memória. In: ACHARD, Pierre et al. (Org.). Papel da memória. Pontes, São Paulo, 1999 [1983]. p. 49-57.

PREDEBON, Aristóteles Angheben. A. Edição do manuscrito e estudo das Metamorfoses de Ovídio traduzidas por Francisco José Freire. Dissertação (Mestrado). Faculdade de Filosofia, Letras e Ciências Humanas. Universidade de São Paulo, São Paulo, 2006.

SAAL, Frida; BRAUNSTEIN, Néstor. El sujeto en el psicoanálisis, el materialismo histórico y la lingüística. In: BRAUNSTEIN, Néstor. Psiquiatría, teoría del sujeto, psicoanálisis (hacia Lacan). Cd. de México: Siglo veintiuno Ed., 2008 [1980]. p. 80-160.

SANTOS, Milton. Da totalidade ao lugar. São Paulo: Editora da Universidade de São Paulo, 2005 [1996].

Forma de citação sugerida:

FORTES, Laura. Sentidos de legitimação do ensino bilíngue português-inglês: efeitos do discurso institucional. EID\&A - Revista Eletrônica de Estudos Integrados em Discurso e Argumentação, Ilhéus, n. 13, p. 104-120, jan/jun.2017.

Recebido em: 28/02/2017

Aprovado em: 30/05/2017 